\title{
An Artificial Neural Network and Taguchi Integrated Approach to the Optimization of Performance and Emissions of Direct Injection Diesel Engine
}

\author{
Venkata Narayana Beeravelli 1*, Ratnam Chanamala 2, Uma Maheswara Rao Rayavarapu ${ }^{3}$, \\ Prasada Rao Kancherla 4
}

${ }^{1}$ Gate Engineering College, Nalgonda, Kodad, INDIA

2 Andhra University, Andhra Pradesh, INDIA

${ }^{3}$ Sasi Institute of Technology and Engineering, Tadepalligudem, Andhra Pradesh, INDIA

${ }^{4}$ NRI Institue, Vijayawada, JNTUK, Andhra Pradesh, INDIA

\section{*Corresponding Author: pulven75@gmail.com}

Citation: Beeravelli, V. N., Chanamala, R., Rayavarapu, U. M. R. and Kancherla, P. R. (2018). An Artificial Neural Network and Taguchi Integrated Approach to the Optimization of Performance and Emissions of Direct Injection Diesel Engine. European Journal of Sustainable Development Research, 2(2), 16. https://doi.org/10.20897/ejosdr/85412

Published: March 8, 2018

\begin{abstract}
Prediction of operating parameters as a function of brake thermal efficiency (BTHE), brake specific fuel consumption (BSFC), carbon monoxide (CO), Hydrocarbons (HC), nitrogen oxide $(\mathrm{NO})$ and Smoke opacity is very important in performance and emission characteristics of the engine. In this study, the effect of operating parameters such as load, blend, compression ratio (CR), injection pressure (IP) and injection timing (IT) on the output responses above mentioned were investigated by using ANN (Artificial neural networks) and trained the signal- to- noise ratio $(\mathrm{S} / \mathrm{N})$ results obtained from Taguchi $\mathrm{L}_{16}$ orthogonal design. These results are compared with the artificial neural network and confirmation test was conducted and the results obtained were well supported.
\end{abstract}

Keywords: artificial neural networks, Taguchi, Karanja methyl ester, signal to noise ratio, absolute prediction error

\section{INTRODUCTION}

Due to the hasty utilization of fossil fuels needed to meet the substantial energy requirements of today's world and the resulting environmental problems, many researchers have focused on finding alternative energy resources and developing new energy conversion systems. Harisankar et al. reported that the results were validated and tested with the experimental HCCI performance and emission metrics. The validation results predicted that the output parameters those lie within $2 \%$ error (Bendu et al., 2016). Amitav et al. developed ANN model to predict BSFC, BTE, NOx, PM, HC and CO based on the experimental results, with load and injection duration as input parameters for the network.

The developed ANN model was capable of predicting the performance and emission parameters with commendable accuracy (Chakraborty et al., 2016). Ganesan et al. proposed ANN (artificial neural network) models for the prediction of carbon dioxide (CO2), CO/CO2 ratio, TF and (h) of DG. The training and testing data required to develop the ANN were obtained through a number of experiments in 3 phases, $415 \mathrm{~V}$, diesel generator (DG) of different capacities operated at different loads, speed and torques. Three different capacities of DGs such as 180, 250, and $380 \mathrm{kVA}$ have been investigated. Back propagation algorithm was used for training the ANN (Ganesan et al., 2015). Ghobadian et al. illustrates that the artificial neural network (ANN) modelling of a diesel 
engine using waste cooking biodiesel fuel to predict the brake power, torque, and specific fuel consumption and exhaust emissions of the engine. To acquire data for training and testing the proposed ANN, two cylinders, fourstroke diesel engine was fuelled with waste vegetable cooking biodiesel and diesel fuel blends and operated at different engine speeds (Ghobadian et al., 2009).

Loftan et al. investigated the combination of artificial neural network (ANN) and non-dominated sorting genetic algorithm II (NSGA-II) has been implemented for modeling and reducing CO and NOx emissions from a direct injection dual-fuel engine. A multi-layer perceptron (MLP) network is developed to predict the values of the emissions based on experimental data. The controllable variables such as engine speed, output power, intake temperature, mass flow rate of diesel fuel, and mass flow rate of the gaseous fuel are considered as input parameters (Lotfan, 2016). Sumit Roy et al. has compared the obtained results with an ANN model developed on the same parametric ranges wherein the GEP model was observed to be superior in predicting the desired response variables (Roy et al., 2014a). Sumit roy et al. explores that the possibility of artificial neural network to predict the performance and exhaust emissions of an existing single cylinder four-stroke CRDI engine under varying EGR strategies. Based on the experimental data an ANN model is developed to predict BSFC, BTE, CO2, NOx and particle matter (PM) with load, fuel injection pressure, EGR and fuel injected per cycle as input parameters for the network (Roy et al., 2014b).

Hadi et al. Carried out investigations 0to assess the potential of applying Artificial Neural Network (ANN) technique to the prediction of n-heptane fueled Direct Injection (DI) Diesel engine emissions of CO2, soot, and Nox (Taghavifar et al., 2015). Sakir et al reported that the results obtained from ANN and Fuzzy expert system (FES) were compared by t-test in SPSS and regression analysis in Matlab, it was determined that both groups of data are consistent with each other for $\mathrm{p}>0.05$ confidence interval and differences were statistically not significant (Tasdemir et al., 2011). Yusuf et al. studied the artificial neural network (ANN) modeling to predict the brake specific fuel consumption, effective power and average effective pressure and exhaust gas temperature of the methanol engine (Çay et al., 2012). Canakci et al. reported that actual and predicted engine performance and exhaust emissions show that the correlation of the actual and predicted values is in good agreement (Canakci et al., 2009). A multi layer perception network (MLP) was used for nonlinear mapping between the input and the output parameters (Najafi et al., 2009). A back- propagation (BP) neural network model with a 3-7-2 (number of input layer-hidden layer-output layer nodes) configuration was developed for predicting specific fuel consumption and exhaust temperature in a Diesel engine. The results were in agreement less than $2 \%$, average relative error with those obtained experimentally (Parlak et al., 2006). Adnam et al. was used an Artificial Neural Networks (ANN) to predict the engine performance and emission characteristics of the engine. Separate models were developed for performance parameters as well as emission characteristics. To train the network, compression ratio, injection timing, blend percentage, percentage load, were used as the input parameters whereas engine performance parameters like brake thermal efficiency (BTE), brake specific energy consumption (BSEC), exhaust gas temperature (EGT) used as the output parameters for the performance model and engine exhaust emissions such as NOx, smoke and (UBHC) values were used as the output parameters for the emission model (Shivakumar et al., 2011). An ANN model was developed to estimate power, torque, fuel consumption and specific fuel consumption.

The comparison of experimental values with those of ANN training estimates (Oğuz et al., 2010). Javed et al. investigates the use of Artificial Neural Network modeling for prediction of performance and emission characteristics of a four stroke single cylinder diesel engine with Jatropha Methyl Ester biodiesel blends along with hydrogen in dual fuel mode. An ANN model was developed to predict BTE, BSFC, $\mathrm{CO}, \mathrm{O}_{2}, \mathrm{CO}_{2}, \mathrm{NOx}, \mathrm{HC}$ and EGT based on initial experimental studies by varying load, blends of biodiesel and hydrogen flow rates. Seven training algorithms each with five combinations of trainings functions were investigated. Levenberg-Marquardt back-propagation, training algorithm with logarithmic sigmoid and hyperbolic tangent sigmoid transfer function results in best model for prediction of performance and emissions characteristics (Syed et al., 2015). In the present study developed a Back-Propagation Neual Network (BPNN) predictive model of a process parameters influencing on performance and emissions of diesel engine. The parameters of ANN model are optimized with Taguchi method. To the best of our knowledge, a predictive model of the performance and emissions of diesel engine with the integration of ANN and Taguchi method has not been studied and is the subject of current study.

\section{MATERIALS AND METHODS}

The present study concentrating on the effect of operating parameters on the engine performance and emission characteristics.

A single cylinder, four stroke, water cooled, direct injection diesel engine is used for experimental tests. The experimental set up is shown in Figure 1, and the test engine specifications are illustrated in Table 1. Exhaust gas emissions are measured by AVL Digas type analyzer, and smoke opacity measured by AVL smokemeter. The 


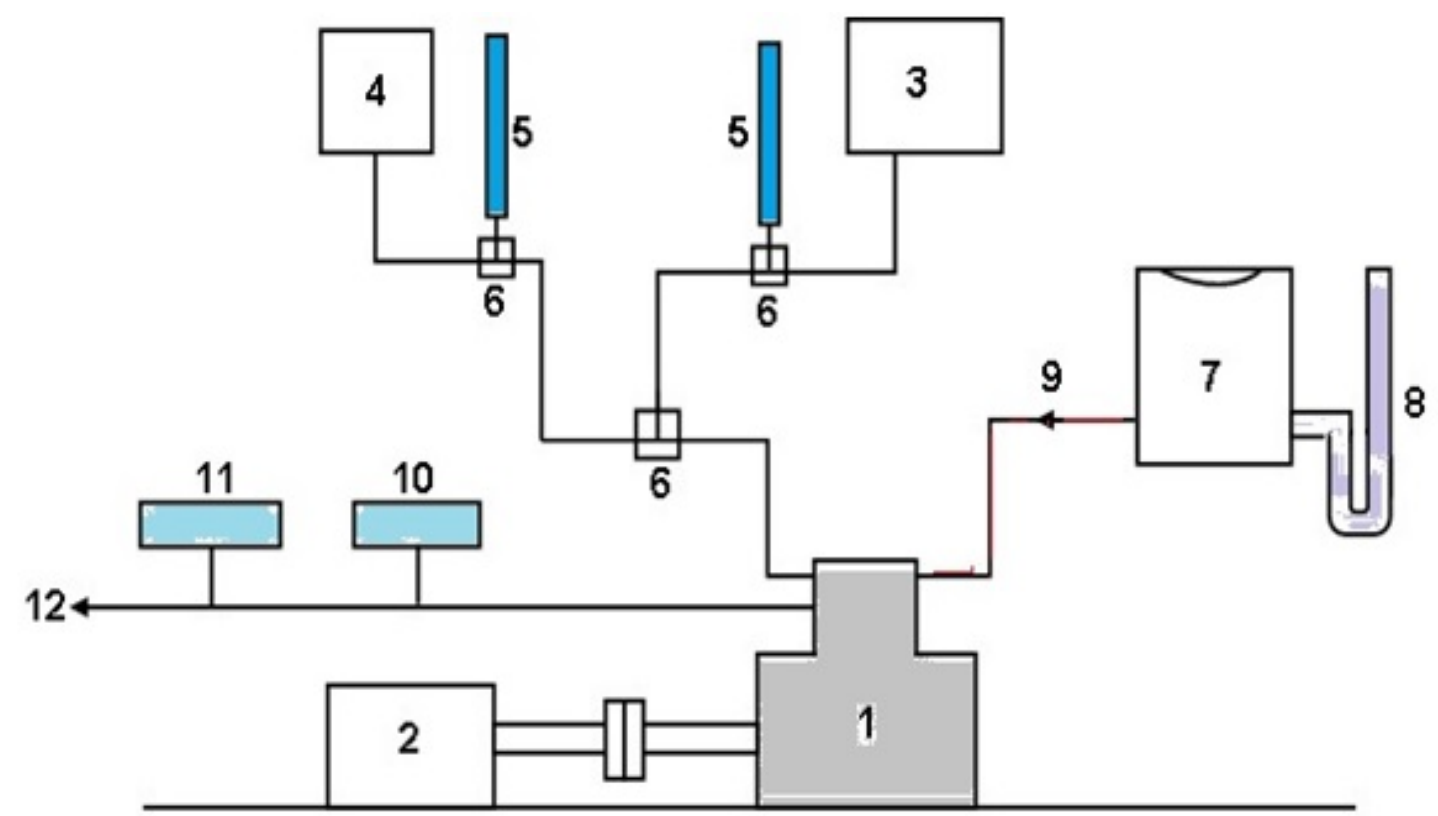

Figure 1. Schematic diagram of testing engine

Table 1. Specifications of the experimental test rig

\begin{tabular}{ll}
\hline Engine & Engine Four stroke, single cylinder, constant speed diesel engine \\
\hline Make & Kirloskar \\
\hline Rated power & $3.75 \mathrm{Kw}$ \\
\hline Speed & $1500 \mathrm{rpm}$ \\
\hline Bore & $87.5 \mathrm{~mm}$ \\
\hline Stroke & $110 \mathrm{~mm}$ \\
\hline Compression ratio & 17.5 \\
\hline Crank angle & Resolution 1degree \\
\hline
\end{tabular}

Table 2. List of actual and corresponding coded values of control factors and their levels

\begin{tabular}{lcccc}
\hline \multirow{2}{*}{ Process parameters } & \multicolumn{3}{c}{ Levels } \\
\cline { 2 - 5 } & 1 & 2 & 3 & 4 \\
\hline Load in $\mathrm{Kg}(\mathrm{A})$ & 4 & 8 & 12 & 16 \\
\hline Blend in $\%(\mathrm{~B})$ & 10 & 20 & 30 & 40 \\
\hline Compression ratio(C) & 17.5 & 17.7 & 17.9 & 18.1 \\
\hline Injection pressure in Bar (D) & 160 & 180 & 200 & 220 \\
\hline Injection time in Degrees (E) & 23 & 25 & 27 & 29 \\
\hline
\end{tabular}

biodiesel fuel used in engine tests is produced from Karanja oil methyl ester (KOME) by transesterification method.

\section{Design of Experiments}

Design of experiments is a most powerful statistical tool (Venkatanarayana and Ratnam, 2017). Taguchi design of experiments method employed to analyze the effect of operating parameters on engine performance and emission characteristics. In this study, five controllable factors such as load, blend, compression ratio, injection pressure and injection timing are chosen each at four levels. Input factors and their levels are shown in Table 2. Taguchi suggested the use of orthogonal arrays, which are the shortest possible matrix of permutations and combinations of the controlling parameters (Venkatanarayana et al., 2017). An orthogonal array $\mathrm{L}_{16}$ has been found suitable for the present design as shown in Table 3. In Taguchi method signal-to-noise ratio values and graphs used to determine optimal process parameters. There are different SNR available build upon the characteristic, such as lower the better (LTB), higher the better (HTB) and nominal the better. In the present study HTB quality characteristics has been used for BTHE, LTB quality characteristic has been employed for BSFC, CO, HC, NOx and smoke opacity. The experimental test have been carried out based on the Taguchi $\mathrm{L}_{16}$ orthogonal design matrix.

\section{Artificial Neural Networks}

A multilayered feed- forward neural network is the most widely used in prediction. In the present study MATLAB software applied to perform, train and validating the experimental results. Trainlm is a training function that updates weight and bias values according to Levenberg-Marquardt optimization. The input layer represents 
Table 3. Taguchi L16 orthogonal array

\begin{tabular}{lccccc}
\hline Trial No. & $\begin{array}{c}\text { A: } \\
\text { Load }\end{array}$ & $\begin{array}{c}\text { B: } \\
\text { Blend }\end{array}$ & $\begin{array}{c}\text { C: } \\
\text { Compression ratio }\end{array}$ & $\begin{array}{c}\text { D: } \\
\text { Injection pressure }\end{array}$ & $\begin{array}{c}\text { E: } \\
\text { Injection time }\end{array}$ \\
\hline $\mathbf{1}$ & 4 & 10 & 17.5 & 160 & 23 \\
\hline $\mathbf{2}$ & 4 & 20 & 17.7 & 180 & 25 \\
\hline $\mathbf{3}$ & 4 & 30 & 17.9 & 200 & 27 \\
\hline $\mathbf{4}$ & 4 & 40 & 18.1 & 220 & 29 \\
\hline $\mathbf{5}$ & 8 & 10 & 17.7 & 200 & 27 \\
\hline $\mathbf{6}$ & 8 & 20 & 17.5 & 220 & 25 \\
\hline $\mathbf{8}$ & 8 & 30 & 18.1 & 160 & 23 \\
\hline $\mathbf{9}$ & 8 & 40 & 17.9 & 220 & 25 \\
\hline $\mathbf{1 0}$ & 12 & 10 & 17.9 & 200 & 23 \\
\hline $\mathbf{1 1}$ & 12 & 20 & 18.1 & 180 & 29 \\
\hline $\mathbf{1 2}$ & 12 & 30 & 17.5 & 160 & 27 \\
\hline $\mathbf{1 4}$ & 12 & 40 & 17.7 & 160 & 27 \\
\hline $\mathbf{1 5}$ & 16 & 10 & 18.1 & 220 & 29 \\
\hline $\mathbf{1 6}$ & 16 & 20 & 17.9 & 200 & 23 \\
\hline
\end{tabular}

Table 4. Summarization of the maximum and minimum values for operating parameters

\begin{tabular}{lcc}
\hline Inputs & Minimum & Maximum \\
\hline Load (Kg) & 4 & 12 \\
\hline Blend (in percentage) & 10 & 40 \\
\hline Compression ratio & 17.5 & 18.1 \\
\hline Injection pressure (Bar) & 160 & 220 \\
\hline Injection timing (in degrees) & 23 & 29 \\
\hline
\end{tabular}

Table 5. Output response and $\mathrm{S} / \mathrm{N}$ ratio values for all experiments

\begin{tabular}{|c|c|c|c|c|c|c|c|c|c|c|c|c|}
\hline Trial No & BSFC & $\mathrm{S} / \mathrm{N}$ & BTH & $\mathbf{S} / \mathbf{N}$ & $\mathrm{CO}$ & $\mathbf{S} / \mathbf{N}$ & $\mathrm{HC}$ & S/N & NOX & $\mathrm{S} / \mathbf{N}$ & SMOKE & $\mathrm{S} / \mathbf{N}$ \\
\hline 1 & 0.24 & -12.52 & 29.46 & 29.38 & 0.63 & -9.57 & 67 & 34.42 & 1304 & 62.3 & 91 & 39.21 \\
\hline 2 & 0.3 & -10.5 & 29.62 & 29.43 & 0.3 & -10.5 & 71 & 33.31 & 1154 & 61.21 & 79 & 37.91 \\
\hline 3 & 0.35 & -9.29 & 29.18 & 29.29 & 0.34 & -9.29 & 88.67 & 33.61 & 1075 & 60.54 & 86 & 38.64 \\
\hline 4 & 0.32 & -9.99 & 28.56 & 29.11 & 0.32 & -9.99 & 59.33 & 34.3 & 1085 & 60.6 & 66 & 36.34 \\
\hline 5 & 0.25 & -12.06 & 33.67 & 30.54 & 0.27 & -12.06 & 64.67 & 34.8 & 1158.3 & 61.22 & 73 & 37.22 \\
\hline 6 & 0.28 & -11.16 & 31.28 & 29.9 & 0.28 & -11.16 & 65.67 & 32.99 & 1266.7 & 62.05 & 90 & 39.11 \\
\hline 7 & 0.35 & -9.15 & 27.17 & 28.68 & 0.32 & -9.02 & 100.33 & 30.36 & 1064.7 & 60.23 & 68 & 36.6 \\
\hline 8 & 0.31 & -10.18 & 29.74 & 29.46 & 0.24 & -10.18 & 115.33 & 30.93 & 1060 & 60.47 & 80 & 38.02 \\
\hline 9 & 0.26 & -11.71 & 30.89 & 29.79 & 0.24 & -11.71 & 73 & 29.71 & 1032.7 & 60.11 & 69 & 36.68 \\
\hline 10 & 0.32 & -10 & 31.14 & 29.86 & 0.26 & -10 & 86 & 32.73 & 988 & 59.61 & 61 & 35.67 \\
\hline 11 & 0.3 & -10.47 & 29.54 & 29.41 & 0.34 & -10.47 & 71.33 & 33.8 & 1215 & 61.69 & 59 & 34.97 \\
\hline 12 & 0.3 & -10.57 & 30.47 & 29.67 & 0.31 & -10.57 & 58 & 33.23 & 1055 & 60.46 & 80 & 38 \\
\hline 13 & 0.27 & -11.29 & 26.96 & 28.61 & 0.23 & -11.29 & 69.33 & 32.22 & 927.33 & 58.94 & 92 & 39.27 \\
\hline 14 & 0.3 & -10.36 & 30.48 & 29.68 & 0.33 & -10.36 & 76 & 34.2 & 1060.7 & 60.39 & 67 & 36.56 \\
\hline 15 & 0.31 & -10.08 & 29.24 & 29.32 & 0.32 & -10.08 & 86.33 & 30.44 & 1135 & 61.08 & 58 & 35.25 \\
\hline 16 & 0.28 & -10.98 & 29.86 & 29.49 & 0.26 & -10.98 & 72.67 & 29.32 & 1156.3 & 60.57 & 48 & 33.59 \\
\hline
\end{tabular}

the condition of the neural network for training. There are distinctive algorithm in the ANN. In the present work, the feed-forward back propagation training algorithm is used. The intention of the ANN modeling is to establish a correlation of input process parameters with output responses. The back propagation neural networks are usually referred to as feed-forwarded and multilayered perceptron with number of hidden layers. The maximum and minimum values for operating parameters used in train for normalization as shown in Table 4. As per the Taguchi L16 orthogonal array, the $\mathrm{S} / \mathrm{N}$ ratio results obtained are used for training, validation and testing presented in Table 5.

\section{Design of the Network Architecture and Training}

Design of the network architecture requires selecting the number of hidden layers, the number of neurons in each layer, the training algorithm and the learning rate that minimize the prediction error or the mean square error (MSE). Figure 2 shows the architecture of the model used in this work. The input parameters are interconnected and the weights of the interconnecting neurons are adjusted to accurately predict the output. Taguchi method is used to select the best architecture (number of neurons in the hidden layers), the training algorithm and the learning rate for the neural network based on the method proposed by Khaw et al. (1995). Once the best architecture is obtained, model testing, validation, and parametric study could be done. We used Levenberg-Marquardt. Two hidden layers were proposed since ANN model with one layer is usually too weak to accurately predict a non-linear function (Asafa et al.). 


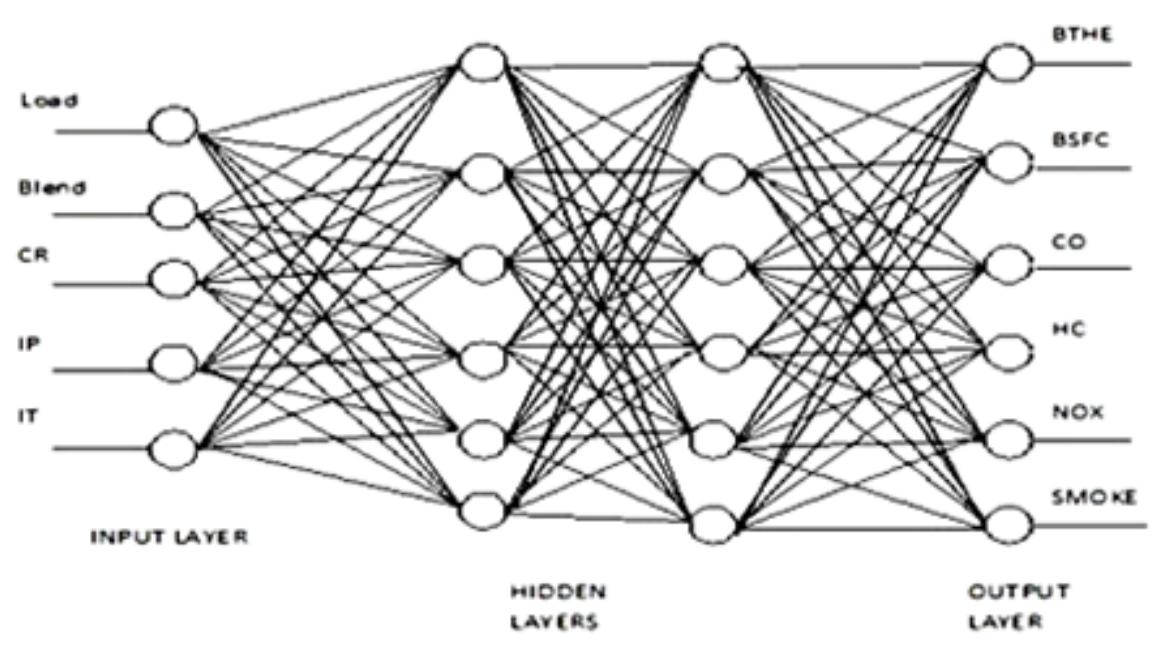

Figure 2. Schematic illustration of the artificial neural network structure used in this work

Table 6. List of ANN predictions with training data set

\begin{tabular}{|c|c|c|c|c|c|c|c|c|c|c|c|}
\hline \multirow{2}{*}{ Trial No. } & \multirow{2}{*}{$\mathbf{A}$} & \multirow{2}{*}{ B } & \multirow{2}{*}{ C } & \multirow{2}{*}{$\mathbf{D}$} & \multirow{2}{*}{$\mathbf{E}$} & \multicolumn{6}{|c|}{ Predicted ANN Values } \\
\hline & & & & & & BSFC & BTHE & $\mathrm{CO}$ & HC & NOX & SMOKE \\
\hline 1 & 4 & 10 & 17.5 & 160 & 23 & -12.52 & 28.61 & -9.0789 & 34.4709 & 59.276 & 39.2238 \\
\hline 2 & 4 & 20 & 17.7 & 180 & 25 & -12.52 & 28.6103 & -10.3895 & 33.3024 & 61.3263 & 37.9282 \\
\hline 3 & 4 & 30 & 17.9 & 200 & 27 & -12.5092 & 29.7045 & -11.8943 & 32.916 & 61.8906 & 37.2243 \\
\hline 4 & 4 & 40 & 18.1 & 220 & 29 & -9.3143 & 30.5207 & -11.4369 & 33.955 & 61.5906 & 35.3739 \\
\hline 5 & 8 & 10 & 17.7 & 200 & 29 & -12.52 & 30.4593 & -11.8898 & 34.6805 & 61.2343 & 37.0987 \\
\hline 6 & 8 & 20 & 17.5 & 220 & 27 & -12.5188 & 29.9626 & -11.1861 & 33.858 & 62.0424 & 39.0177 \\
\hline 7 & 8 & 30 & 18.1 & 160 & 25 & -12.52 & 28.61 & -9.2909 & 30.5113 & 60.2418 & 37.0263 \\
\hline 8 & 8 & 40 & 17.9 & 180 & 23 & -12.52 & 28.61 & -10.2761 & 31.1112 & 60.5282 & 38.2522 \\
\hline 9 & 12 & 10 & 17.9 & 220 & 25 & -12.52 & 28.6105 & -9.2912 & 31.4938 & 59.3402 & 39.0347 \\
\hline 10 & 12 & 20 & 18.1 & 200 & 23 & -12.52 & 28.61 & -9.1999 & 32.3033 & 59.5032 & 35.3985 \\
\hline 11 & 12 & 30 & 17.5 & 180 & 29 & -12.52 & 29.4454 & -10.3084 & 33.7522 & 61.6023 & 35.4242 \\
\hline 12 & 12 & 40 & 17.7 & 160 & 27 & -12.52 & 29.2823 & -10.6482 & 32.6582 & 61.0566 & 34.6576 \\
\hline 13 & 16 & 10 & 18.1 & 180 & 27 & -12.52 & 28.61 & -9.1904 & 32.1659 & 59.0258 & 39.1588 \\
\hline 14 & 16 & 20 & 17.9 & 160 & 29 & -12.52 & 28.6187 & -10.3476 & 30.8114 & 59.555 & 38.2878 \\
\hline 15 & 16 & 30 & 17.7 & 220 & 23 & -12.52 & 28.6127 & -9.9339 & 30.82 & 60.4172 & 36.4683 \\
\hline 16 & 16 & 40 & 17.5 & 200 & 25 & -12.5174 & 29.4073 & -11.0238 & 29.4293 & 62.0012 & 33.8401 \\
\hline
\end{tabular}

\section{Taguchi Technique for Selection of Optimal ANN Parameters}

Five process parameters of ANN model were identified as most important variables for optimizing the model performance.

\section{RESULTS AND DISCUSSION}

To increase the accuracy and speed of the network, the SNR values obtained from Taguchi method is used in the training, testing and validating phase. There are six responses formed separately. The error plot for performance is shown in Figure 9, and same kind of trend is also obtained in case of emissions.In the present study, it was observed that the artificial neural network (ANN) model yields more admissible results when compared with the results obtained in Taguchi method.

ANN model is trained and validated by using $\mathrm{S} / \mathrm{N}$ ratio results obtained from Taguchi method and the other combination of experiments are not performed, can be predicted by using this present model, which can reduce the cost and time.

The ANN model was developed to predict the performance and emissions are given in Figure 2. The ANN approach presented for the performance and emission characteristics of the engine gives desired results. S/N ratios which are expressed in a decibel scale, computed from the quadratic (quality) loss function. The $\mathrm{S} / \mathrm{N}$ ratios are calculated for each experiment. The term 'signal' indicates the mean value and the term 'noise' indicates the variance value (undesirable) for the output response of the process. This technique is used to identify the controllable factors that reduce the effect of the uncontrollable (noise) factors on the response. The chosen factors with the highest $\mathrm{S} / \mathrm{N}$ ratio would give the optimum quality with the least variance. When the $\mathrm{S} / \mathrm{N}$ ratio vs factor levels curve shifts from one level to another level from the Figures 3-8 show the significance level of each 


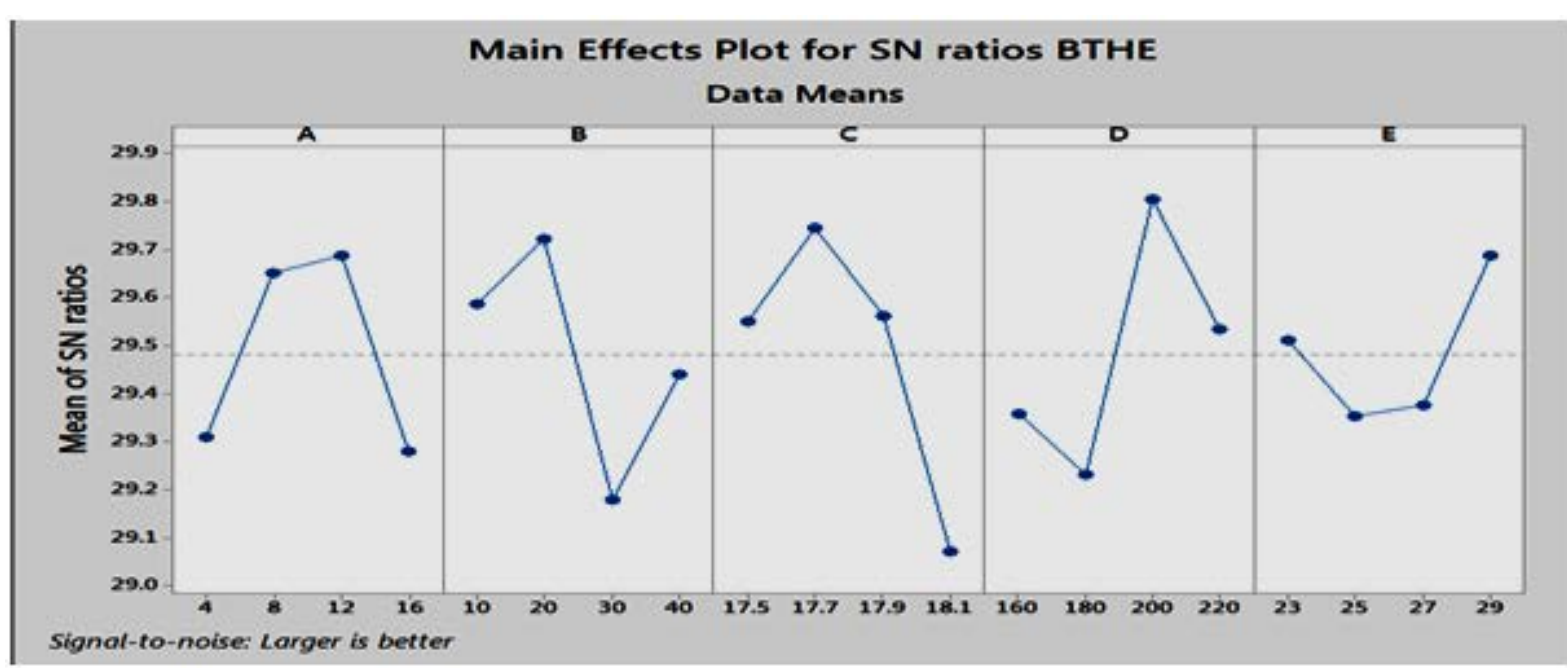

Figure 3. S/N graph for brake thermal efficiency

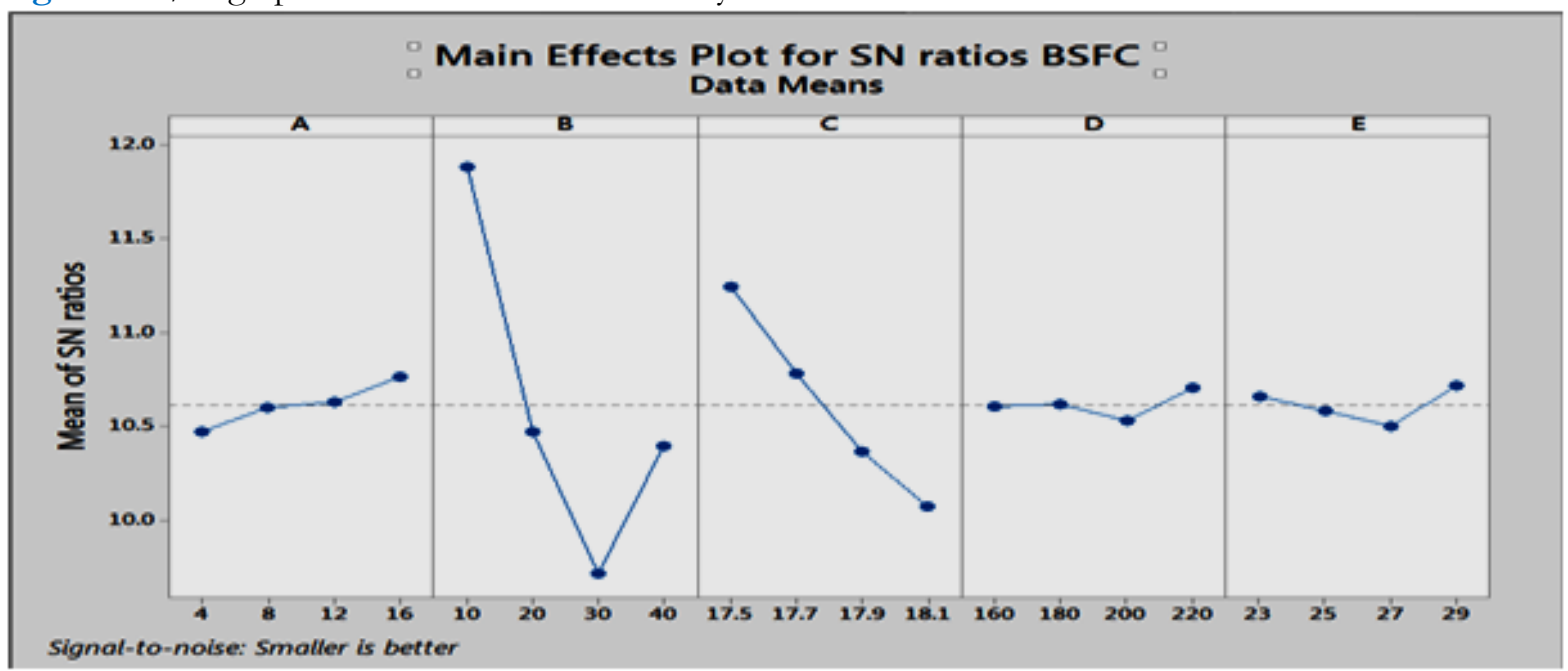

Figure 4. S/N graph for brake specific fuel consumption

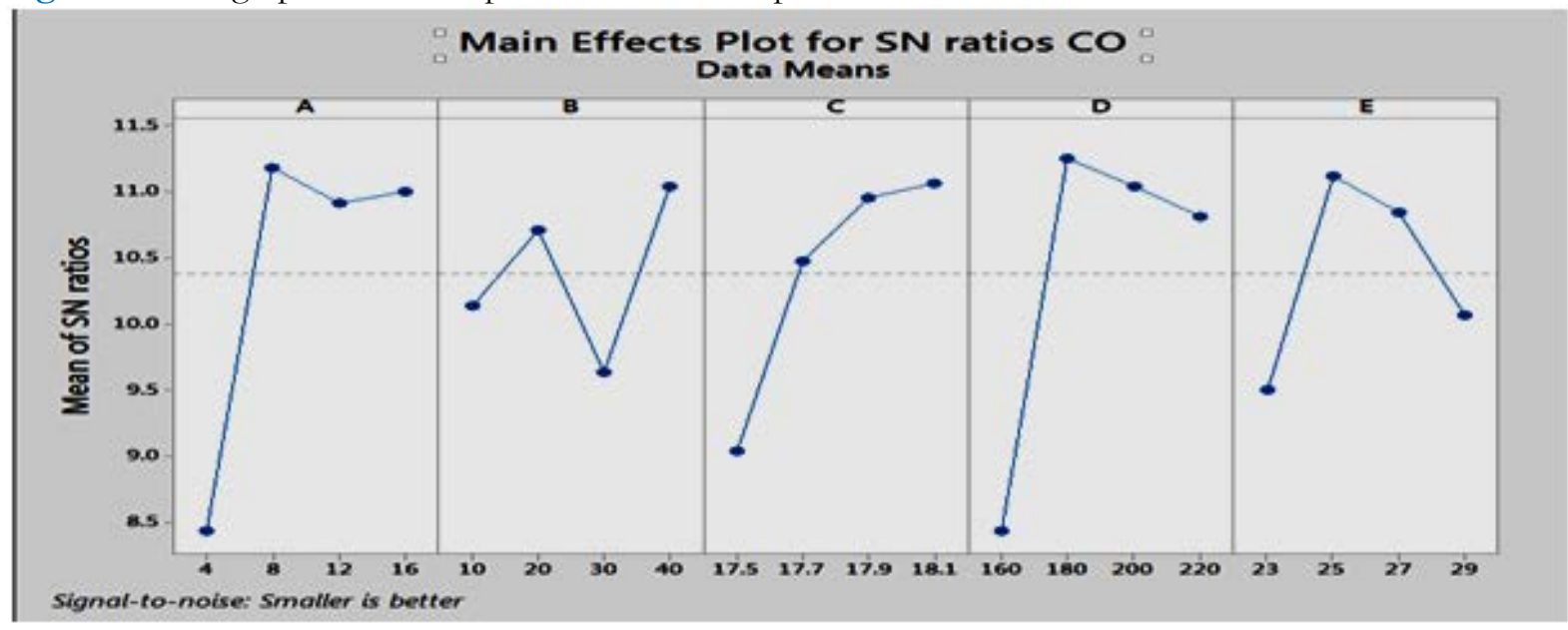

Figure 5. S/N graph for carbon monoxide

parameter. Optimal engine parameters for BTHE, BSFC, CO, HC, NOX and Smoke were obtained A3B2C2D3E4, A1B3C4D3E3, A1B3C4D3E3, A2B3C3D1E1, A1B3C1D4E2 and A1B1C3D2E3.

A typical example of the convergence of the testing and training networks performance and emissions is shown in Figure 9 and 10. The best validation performance of 6.991 is obtained after 6 iterations. The coefficients of regression are 0.99 and 0.99 for training and testing data, respectively. These coefficients are statistically satisfactory. The ANN predicted values are shown in Table 6.

Figure 10(a-d) depicts the scatter plots of training phase for modeling results compared against actual experimental data. The ideal fitting line is in the linear first order format of $y=a x+b$. The values of (a) and (b) coefficients are set close to 1 and 0 , respectively. The results of modeling through network procedure were mapped 


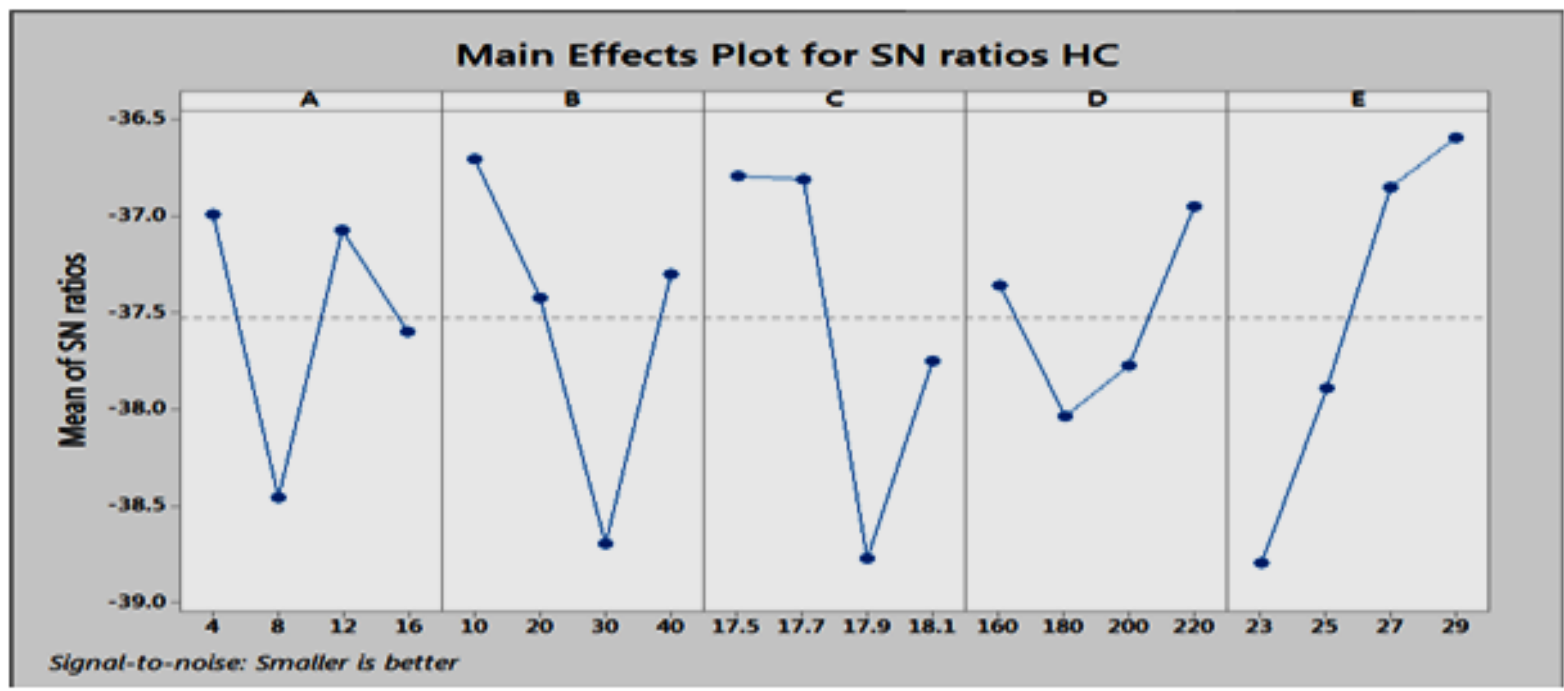

Figure 6. S/N graph for Hydrocarbons

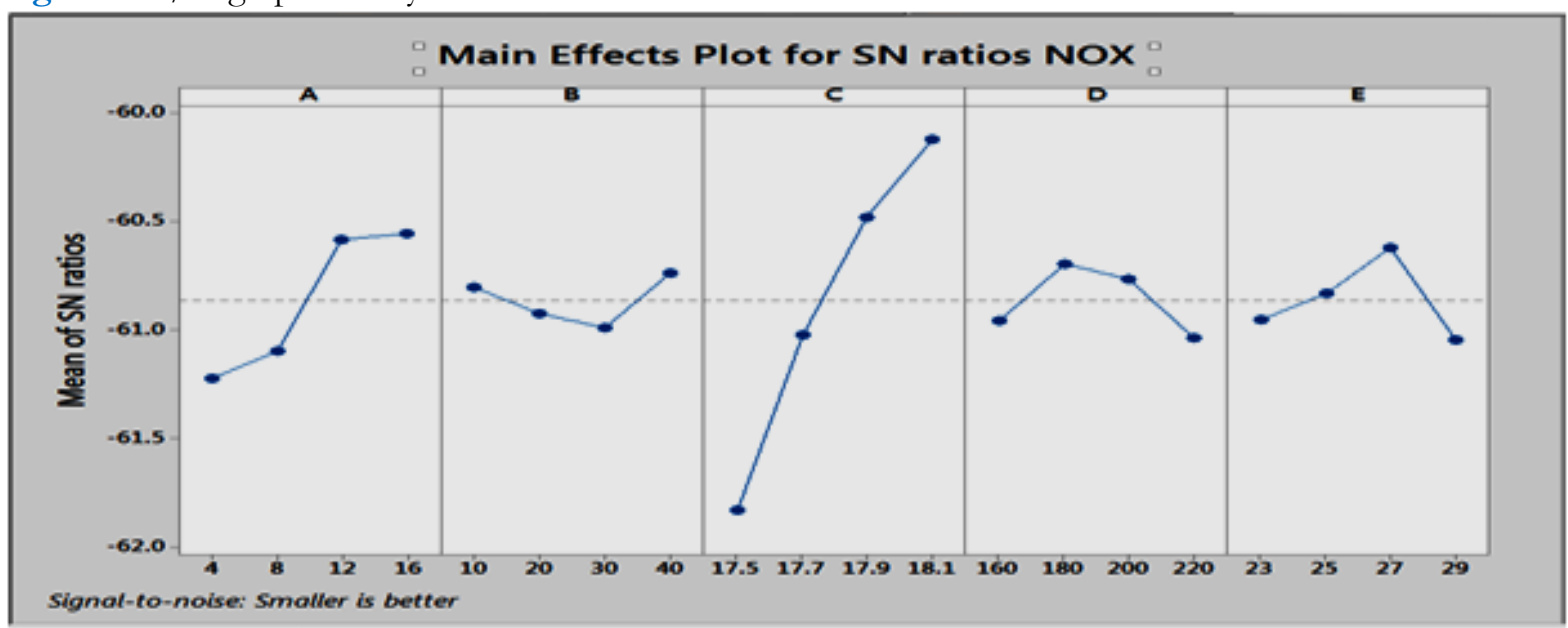

Figure 7. S/N graph for $\mathrm{NO}_{\mathrm{x}}$

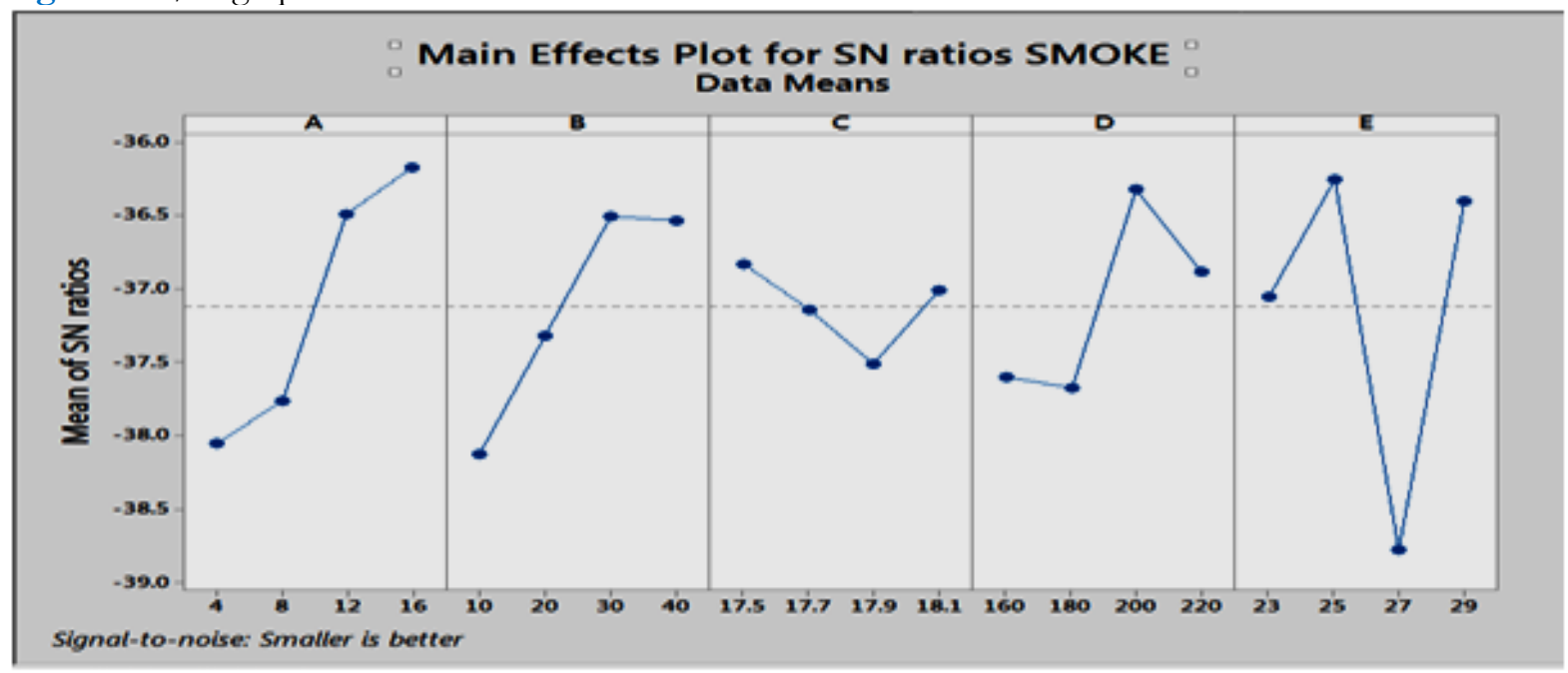

Figure 8. S/N graph for Smoke opacity

out close to the line, entailing the accuracy and efficiency of the ANN methodology. The correlation coefficients concerning regression analysis between corresponding targets and network responses are 0.99949, 0.99848, 0.99792, 0.99173, and 0.99682 for training, testing, validation and all respectively. The best correlation can be appreciated for training due to the fact that the data were more evenly distributed along the fitness line, hence better correlation was accomplished. Thereby, it can be noticed that ANN simulation offers simple and accurate responses in relation to numerical methods especially in dealing with multivariate, nonlinear problems where no specific data were elaborated concerning system attributes. 
Table 7. Validation of the ANN prediction results

\begin{tabular}{lcccc}
\hline Responses & Optimum condition & Experimental S/N Value & Predicted S/N Value & APE (\%) \\
\hline BTHE & A3B2C3D3E4 & 29.67 & 29.22 & 1.516684 \\
\hline BSFC & A1B3C4D3E3 & -9.85 & -11.57 & -17.4619 \\
\hline CO & A1B3C1D1E1 & -10.15 & -10.51 & -3.5468 \\
\hline HC & A1B2C2D1E4 & 32.32 & 32.08 & 0.742574 \\
\hline NOX & A1B3C1D4E4 & 60.81 & 60.82 & -0.01644 \\
\hline SMOKE & A1B1C3D2E3 & 36.01 & 35.93 & 0.222161 \\
\hline
\end{tabular}

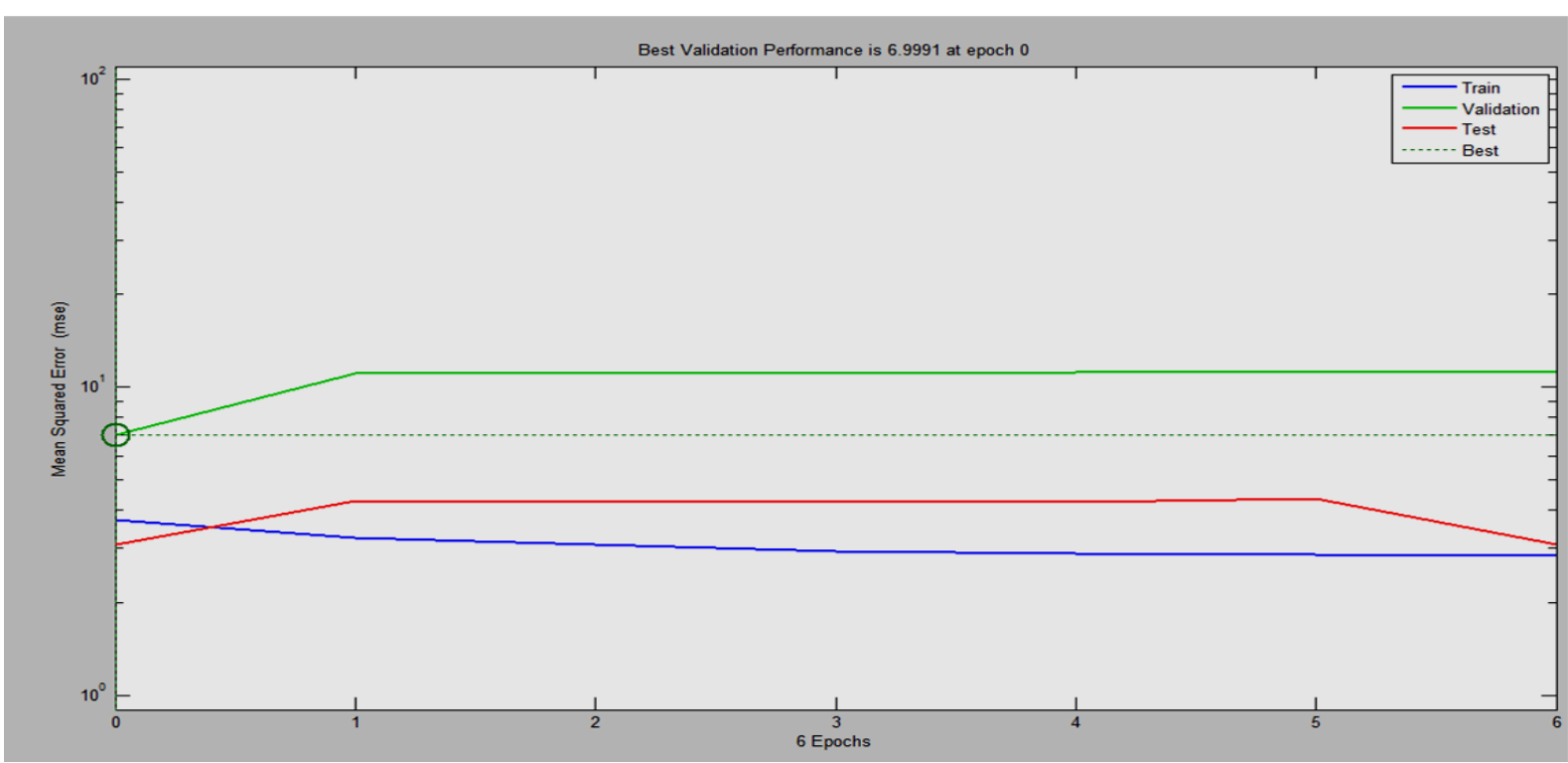

Figure 9. Illustrates the training performance

The ANN predictions for the performance and emissions of the tested diesel engine yielded a good statistical performance. Comparisons of the experimental results and the ANN predictions demonstrate that diesel engine using KOME fuel can be accurately simulated using ANN. The predicted vs experimental values for performance and emissions indicated in Figure 10(a-d).

The confirmation test is the final step in the Taguchi method. Confirmation experiment was desirable because the optimum combination for BTHE, BSFC, CO, HC, NOX and Smoke opacity were verified in this experiment. The optimum combinations of experiments were verified by conducting the confirmation experiment with the predicted ANN results.

The optimum levels of design parameters are used for the prediction of performance and emissions response variables and thereby comparison with the experimental results. The estimated $\mathrm{S} / \mathrm{N}$ ratio $\mathrm{T}_{\mathrm{m}}$ at the optimal level of the design parameters can be calculated as

$$
\mathrm{T}=\mathrm{T}_{\mathrm{m}}+\sum_{\mathrm{i}=1}^{\mathrm{n}}\left[\mathrm{X}_{\mathrm{I}}-\mathrm{T}_{\mathrm{m}}\right]
$$

where $T_{m}$ is the total mean $S / N$ ratio, $X_{I}$ is the mean $S / N$ ratio at the optimal level, and $n$ is the number of main design parameters that affect the quality characteristics. For validation of the predicted results at optimum condition, experiments are conducted as per the optimum condition and the average results are reasonably close to the predicted results. The absolute prediction error (APE) has been calculated using the following formula and presented in Table 7.

$$
\text { Absolute prediction error }(\text { APE })=\left|\frac{\text { Experimental }- \text { Predicted }}{\text { Experimental }}\right| * 100 \%
$$

\section{CONCLUSIONS}

In the present study, an ANN approach was developed for direct injection diesel engine using the $\mathrm{S} / \mathrm{N}$ results obtained at different operating parameters. The tests were performed using Karanja methyl ester as a fuel and Taguchi $\mathrm{L}_{16}$ was the orthogonal design. 

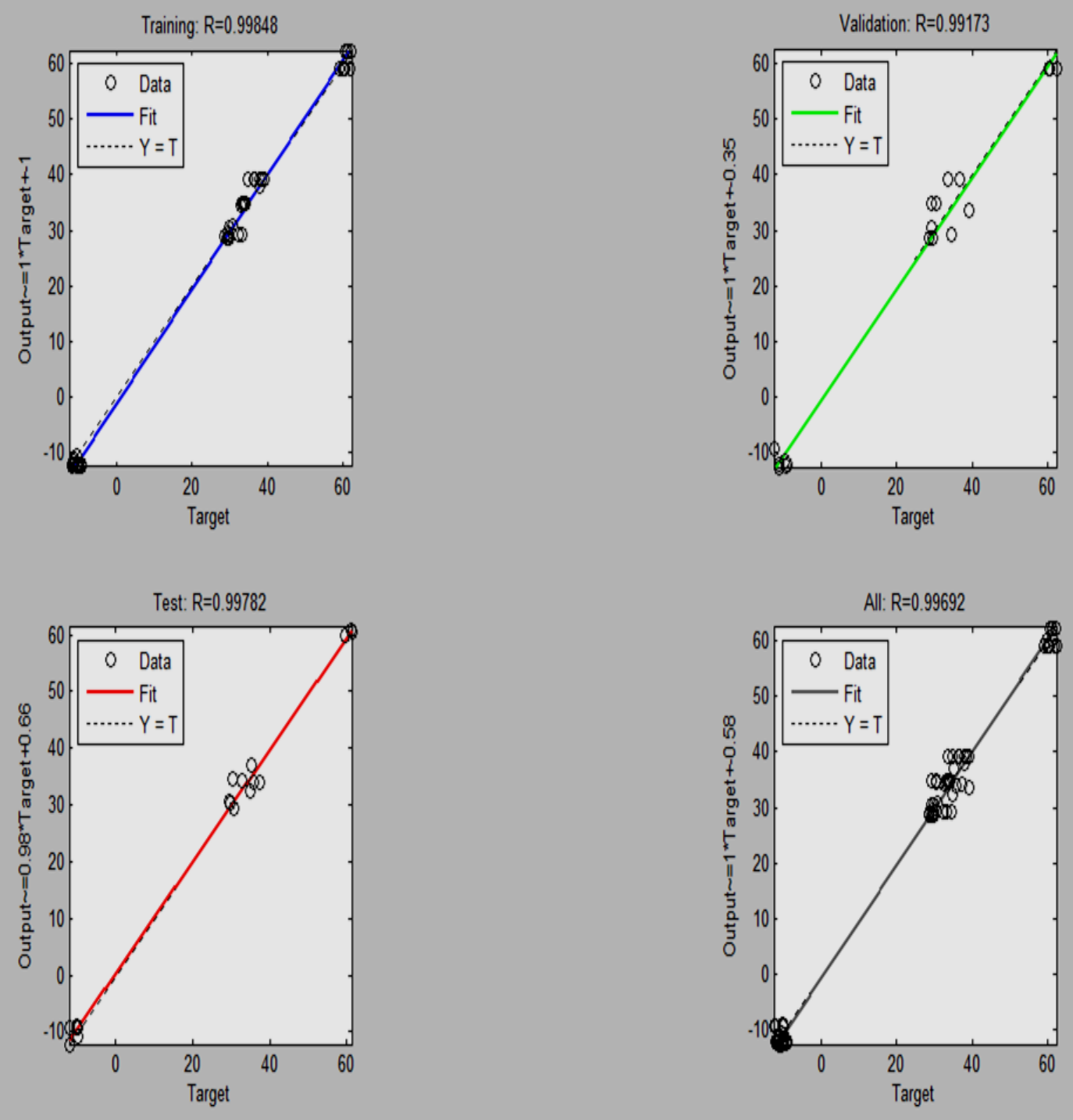

Figure 10 (a-d). Regression analysis of performance and emissions

The optimum combination factor levels were obtained using Taguchi experimental design BTHE (33.32\%), BSFC $(0.35 \mathrm{Kg} / \mathrm{Kwh})$ and exhaust emissions such as CO (0.38\%), HC (121.75 ppm), NOx (1265.38ppm) and Smoke opacity (109.66 ppm).

The ANN model based on the feed-forward back propagation network algorithm was designed for predicting the performance and emissions of the direct injection diesel engine. The predicted values have been found to be very close to the experimental results.

\section{REFERENCES}

Asafa, T. B., Bryce, G., Severi, S. and Said, S.A.M. Witvrouw, Multi-response optimization of ultrathin poly-SiGe Films characteristics for nano- electromechanical systems (NEMS) using the grey-Taguchi technique. J. Microelectron. Eng., submitted for publication.

Canakci, M., Ozsezen, A. N., Arcaklioglu, E. and Erdil, A. (2009). Prediction of performance and exhaust emissions of a diesel engine fueled with biodiesel produced from waste frying palm oil. Expert Systems with Applications, 36, 9268-9280. https:// doi.org/10.1016/j.eswa.2008.12.005

Chakraborty, A., Roy, S. and Banerjee, R. (2016). An experimental based ANN approach in mapping performanceemission characteristics of a diesel engine operating in dual-fuel mode with LPG. Journal of Natural Gas Science and Engineering, 28, 15-30. https://doi.org/10.1016/j.jngse.2015.11.024

Çay, Y., Çiçek, A., Kara, F. and Sagiroglu, S. (2012). Prediction of engine performance for an alternative fuel using artificial neural network. Applied Thermal Engineering, 37, 217-225. https://doi.org/10.1016/j.applthermaleng.2011.11.019 
Ganesan, P., Rajakarunakaran, S., Thirugnanasambandam, M. and Devaraj, D. (2015). Artificial neural network model to predict the diesel electric generator performance and exhaust emissions. Energy, 83. https://doi.org/10.1016/j.energy.2015.02.094

Ghobadian, B., Rahimi, H., Nikbakht, A. M., Najafi, G. and Yusaf, T. F. (2009). Diesel engine performance and exhaust emission analysis using waste cooking biodiesel fuel with an artificial neural network. Renewable Energy, 34, 976-982. https://doi.org/10.1016/j.renene.2008.08.008

Harisankar, B., Deepak, B. B. V. L. and Murugan, S. (2016). Application of GRNN for the prediction of performance and exhaust emissions in HCCI engine using ethanol. Energy Conversion and Management.

Khaw, J. F. C., Lim, B. S. and Lim, L. E. N. (1995). Optimal design of neural network using the Taguchi method. Neurocomputing, 7, 225-245. https:// doi.org/10.1016/0925-2312(94)00013-I

Lotfan, S., Akbarpour Ghiasi, R., Fallah, M., Sadeghi, M. H. (2016). ANN-based modeling and reducing dual-fuel engine's challenging emissions by multi-objective evolutionary algorithm NSGA-II. Applied Energy, 175, 91-99. https://doi.org/10.1016/j.apenergy.2016.04.099

Najafi, G., Ghobadian, B., Tavakoli, T., Buttsworth, D. R., Yusaf, T. F. and Faizollahnejad, M. (2009). Performance and exhaust emissions of a gasoline engine with ethanol blended gasoline fuels using artificial neural network. Applied Energy, 86, 630-639. https://doi.org/10.1016/j.apenergy.2008.09.017

Oğuz, H., Saritas, I. and Baydan, H. E. (2010). Prediction of diesel engine performance using biofuels with artificial neural network. Expert Systems with Applications, 37, 6579-6586. https://doi.org/10.1016/j.eswa.2010.02.128

Parlak, A., Islamoglu, Y., Yasar, H. and Egrisogut, A. (2006). Application of artificial neural network to predict specific fuel consumption and exhaust temperature for a Diesel engine. Applied Thermal Engineering, 26, 824828. https://doi.org/10.1016/j.applthermaleng.2005.10.006

Roy, S., Ghosh, A., Das, A. K. and Banerjee, R. (2014). A comparative study of GEP and an ANN strategy to model engine performance and emission characteristics of a CRDI assisted single cylinder diesel engine under CNG dual-fuel operation. Journal of Natural Gas Science and Engineering, 21, 814-828. https://doi.org/10.1016/j.jngse.2014.10.024

Roy, S., Banerjee, R. and Bose, P. K. (2014). Performance and exhaust emissions prediction of a CRDI assisted single cylinder diesel engine coupled with EGR using artificial neural network. Applied Energy, 119, 330-340. https://doi.org/10.1016/j.apenergy.2014.01.044

Shivakumar S. P. P. and Shrinivasa, R. B. R. (2011). Artificial Neural Network based prediction of performance and emission characteristics of a variable compression ratio CI engine using WCO as a biodiesel at different injection timings. Applied Energy, 88, 2344-2354. https://doi.org/10.1016/j.apenergy.2010.12.030

Syed Javed, Y. V. V., Satyanarayana, M., Rahmath, U. B. and Rao, D. P. (2015). Development of ANN model for prediction of performance and emission characteristics of hydrogen dual fueled diesel engine with Jatropha Methyl Ester biodiesel blends. Journal of Natural Gas Science and Engineering, 26, 549-557. https://doi.org/10.1016/j.jngse.2015.06.041

Taghavifar, H., Mardani, A., Khalilarya, A. M. S. and Jafarmadar, S. (2015). Appraisal of artificial neural networks to the emission analysis and prediction of $\mathrm{CO} 2$, soot, and NOx of $\mathrm{n}$-heptane fueled engine. Journal of Cleaner Production $\times x \times, 1-11$.

Tasdemir, S., Saritas, I., Ciniviz, M. and Allahverdi, N. (2011). Artificial neural network and fuzzy expert system comparison for prediction of performance and emission parameters on a gasoline engine. Expert Systems with Applications, 38, 13912-13923. https://doi.org/10.1016/j.eswa.2011.04.198

Venkatanarayana, B. and Ratnam, C. (2017). Selection of optimal performance parameters of DI diesel engine using Taguchi approach. Biofuels, Biofuels, Taylor \& Francis. https:// doi.org/10.1080/17597269.2017.1329492

Venkatanarayana, B., Ratnam, C., Rao, R. U. and Rao, K. P. (2017). Multi-response optimization of DI diesel engine performance parameters using Karanja methyl ester by applying Taguchi-based principal component analysis. Biofuels, Taylor \& Francis, 8(1), 49-57. https://doi.org/10.1080/17597269.2016.1200863 